\title{
Quantitative assessment of the rheumatoid synovial microvascular bed by gadolinium-DTPA enhanced magnetic resonance imaging
}

\author{
Karl Gaffney, John Cookson, Selina Blades, Adam Coumbe, David Blake
}

\begin{abstract}
Objective-To examine the relation between rate of synovial membrane enhancement, intra-articular pressure (IAP), and histologically determined synovial vascularity in rheumatoid arthritis, using gadolinium-DTPA enhanced magnetic resonance imaging (MRI).

Methods-Dynamic gadolinium-DTPA enhanced MRI was performed in 31 patients with knee synovitis (10 patients IAP study, 21 patients vascular morphometry study). Rate of synovial membrane enhancement was quantified by line profile analysis using the image processing package ANALYZE. IAP was measured using an intra-compartmental pressure monitor system. Multiple synovial biopsy specimens were obtained by a blind biopsy technique. Blood vessels were identified immunohistochemically using the endothelial cell marker QBend30 and quantified (blood vessel numerical density and fractional area).
\end{abstract}

Results-Median blood vessel numerical density and fractional area were $77.5 / \mathrm{mm}^{2}$ (IQR; 69.3-110.7) and 5.6\% (IQR; 3.4-8.5) respectively. The rate of synovial membrane enhancement (median 2.74 signal intensity units/s, IQR 2.0-3.8) correlated with both blood vessel numerical density $(r=0.46, p<0.05)$ and blood vessel fractional area $(r=0.55, \mathrm{p}<0.02)$. IAP did not influence the rate of enhancement. Conclusions-Gadolinium-DTPA enhanced MRI may prove to be a valuable technique for evaluating drugs that influence angiogenesis.

(Ann Rheum Dis 1998;57:152-157)

Bone and Join

K Gaffney

$S$ Blades

A Coumbe

D Blake

and Hill Centre

J Cookson

St Bartholomew's and The Royal London School of Medicine and Dentistry, London

Correspondence to: Dr K Gaffney, Department of Rheumatology, Norfolk and Norwich Hospital, Norwich, Norfolk NR1 3SR.

Accepted for publication 13 January 1998 onstrating inflammatory synovial eration in rheumatoid arthritis (RA). ${ }^{1-4}$ Rate of contrast enhancement has been shown to correlate with the inflammatory activity of the proliferating synovium, ${ }^{1-3}$ and is significantly reduced after intra-articular glucocorticoid installation. ${ }^{5}$ The technique has also been proposed as being superior to clinical or radiographic techniques for evaluating disease progression and may have prognostic value with regard to the future development of bone destruction. ${ }^{6}{ }^{7}$
Inflammation is characterised by increased tissue perfusion and capillary permeability. Synovial uptake of Gd-DTPA (enhancement) is dependent on local tissue perfusion and microvascular permeability, ${ }^{8}$ resulting in leakage of intravenously injected contrast medium into the interstitial space. This is manifest as increased signal intensity (brightness) on T1weighted MR images. We have previously described a method for defining the "synovium-only" phase of Gd-DTPA uptake in the synovium of patients with RA using the image processing package "ANALYZE", and demonstrated a significant correlation between rate of synovial membrane enhancement and certain histopathological features of synovitis; polymorphonuclear leucocyte infiltration, hyperaemia, fibrin deposition. ${ }^{1}$ It has been proposed that it may be possible to grade the vascularity of proliferative synovitis using this technique, and therefore differentiate "active" hypervascular, pathologically permeable, inflammatory synovial proliferation from noninflammatory, "inactive" fibrous tissue. ${ }^{3}$ No study however has attempted to quantitatively validate this hypothesis.

The rate of transport of small plasma solutes such as Gd-DTPA into the synovial bed and joint fluid depends on multiple factors; systemic blood pressure and vascular resistance, the flow of fluid from the synovial bed to the joint space and clearance thereof, synovial permeability, and the concentration gradient across the synovium. The net flow of solutes and fluid is therefore largely determined by the balance between the osmotic and hydraulic pressures within the capillaries and joint space..$^{10}$ Intra-articular pressure (IAP) is raised in patients with $\mathrm{RA}^{11}{ }^{12}$ and can theoretically compromise synovial microvascular blood flow. For these reasons, the influence of IAP on synovial membrane enhancement needs to be evaluated.

This study was designed to develop a quantitative technique for assessing synovial vascularity based upon Gd-DTPA enhanced MRI and discover if IAP can compromise the validity of the technique.

\section{Methods}

PATIENTS

All study protocols were considered and approved by the City and East London Research Ethics Committee. Patients fulfilled the American College of Rheumatology criteria for the diagnosis of RA, ${ }^{13}$ and were recruited from a general rheumatology clinic. All 

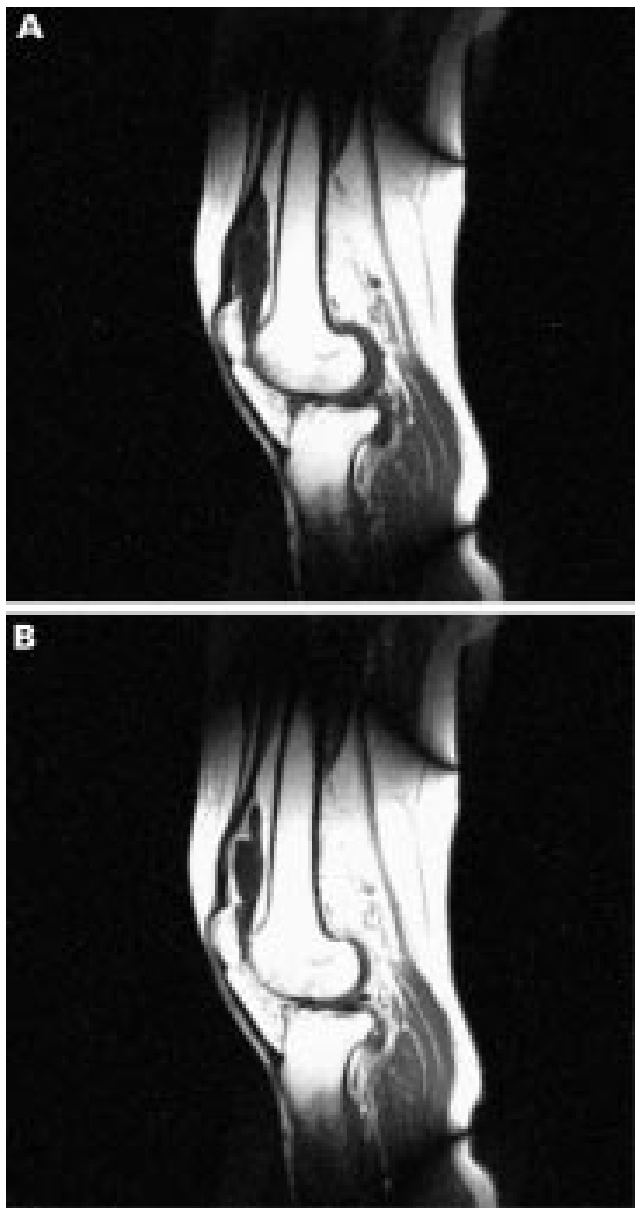

Figure 1 Sagittal section through a rheumatoid knee joint before and after intravenous administration of gadolinium-DTPA.

presented with a "disease flare" as defined by an Index of Disease Activity (IDA) greater than $2,{ }^{14}$ and clinical evidence of knee synovitis (pain, tenderness, joint effusion; positive bulge sign and patellar tap). In patients with bilateral knee synovitis, the most painful joint was selected for study. Informed written consent was obtained from all participants.

MRI PROTOCOL

Imaging was performed using a 0.5 Magnetom Unit (Shimadzu Medical Systems, Tokyo, Japan) equipped with a dedicated cylindrical knee coil. During the examination, patients were placed in the supine position with the knee fully extended in the neutral position. A dynamic T1 weighted spin echo sagittal sequence was obtained through the suprapatellar bursa (TR/TE 180/20 ms, FOV $30 \mathrm{~cm}, \mathrm{Ma}$ $256 \times 256$, four slices, slice thickness $5 \mathrm{~mm}$, imaging time 48 seconds, 16 loops). Immediately after the acquisition of baseline images (1st loop), bolus intravenous Gd-DTPA (0.1 $\mathrm{mmol} / \mathrm{kg}$ body weight; Nycomed, UK) was administered via a $21 \mathrm{G}$ butterfly needle inserted into an ante-cubital fossa vein. The total imaging time was 12 minutes 46 seconds.

MRI QUANTIFICATION

Data were transferred from the MRI console to a SUN workstation and analysed using the image processing package ANALYZE from the

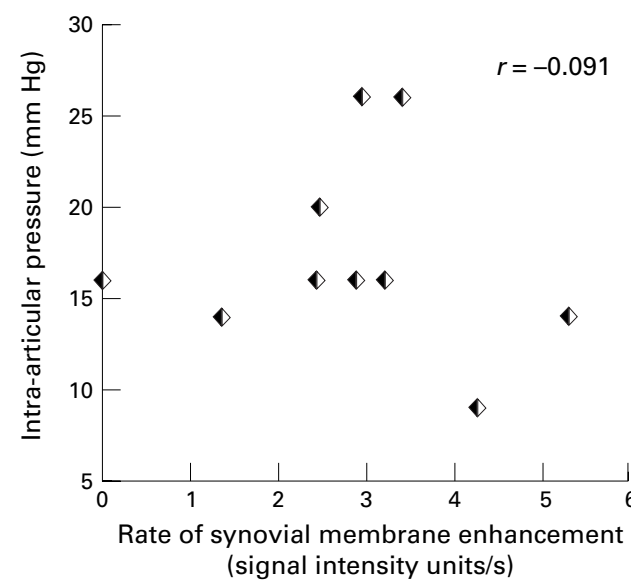

Figure 2 Relation between rate of synovial membrane enhancement and resting intra-articular pressure.

Mayo clinic (15; CN Software Inc, Rochester, Minnesota, USA). Significant patient knee movement was assessed by performing line profile analysis in two orthogonal planes as outlined in previous studies. ${ }^{1}$ Line profile measurements were conducted in synovium lining the anterior surface of the suprapatellar bursa. The voxel demonstrating the maximum rate of enhancement (increase in voxel signal intensity/time) in the initial linear phase of development of increased signal intensity $\left(\mathrm{SI}_{\mathrm{t}}\right.$ $-\mathrm{SI}_{\mathrm{o}} / \mathrm{t}$ ) was recorded in each line profile, where $\mathrm{SI}_{\mathrm{t}}$ is the signal intensity obtained $\mathrm{t}$ seconds after contrast injection, $\mathrm{SI}_{\mathrm{o}}$ is the signal intensity in the first non-enhanced image, and $t$ is the time taken to reach peak enhancement in the initial linear phase of development of increased signal intensity. Four approximately equidistant sample sites were selected for line profile analysis in each of the four slices, extending from apex to inferior pole of the suprapatellar bursa and without specific reference to apparent synovial thickness at any site. This provided 16 readings for each patient from which the median value for rate of synovial membrane enhancement was calculated. To assess reproducibility of the system, MR data analysis was undertaken on two occasions in 10 randomly selected patients (160 measurements).

\section{CONSECUTIVE DAY MRI}

Studies were undertaken to assess the reproducibility of MRI as an imaging technique. Five female patients were recruited to undergo MRI on consecutive days. The median patient age and disease duration were 58 years (range 41-78) and 10 years (8-41) respectively. All patients were seropositive (rheumatoid factor $>40 \mathrm{iu} / \mathrm{l}$ ) and had radiographic evidence of bone erosion as assessed by standard hand and feet radiographs.

INTRA-ARTICULAR PRESSURE STUDY

IAP was measured in the knee joints of 10 patients; 8 female, median age 60 years (range 40-78), median disease duration 12 years (range 7-41) and recorded in $\mathrm{mm} \mathrm{Hg}$. Five of these patients also participated in the consecutive day MRI study and were recruited at the 


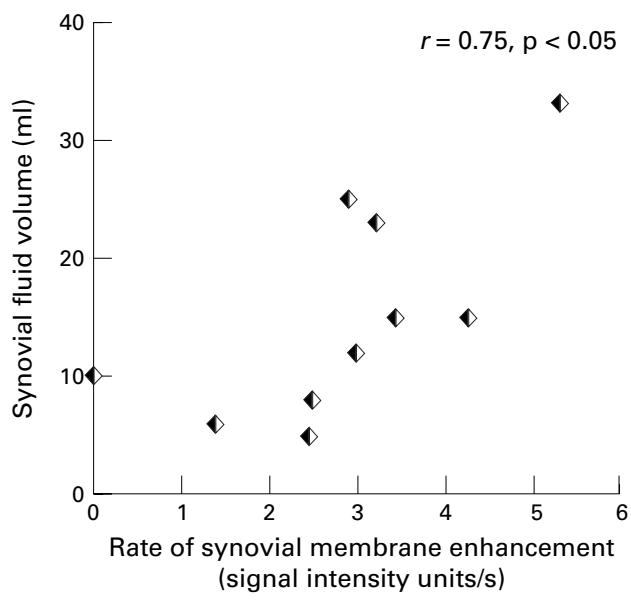

Figure 3 Relation between rate of synovial membrane enhancement and volume of synovial fluid aspirated.

time of the day $2 \mathrm{MR}$ examination. IAP was measured immediately after MR examination before the patient was moved from the examination couch using the hand held portable 295-1 Intra-Compartmental Pressure Monitor System (Stryker, UK). This method is outlined in our previous IAP studies. ${ }^{12}$ Immediately after the procedure, the joint was aspirated to dryness and volume of synovial fluid recorded.

\section{VASCULAR MORPHOMETRY STUDY}

Patients

Twenty one patients; 14 female, median age 58 years (range 37-72), median disease duration 15 years (range 1-38) were recruited. Clinical, laboratory, and semi-quantitative histological data derived from these patients has previously been reported. ${ }^{1}$ Seventeen patients had seropositive disease and 19 had radiographic

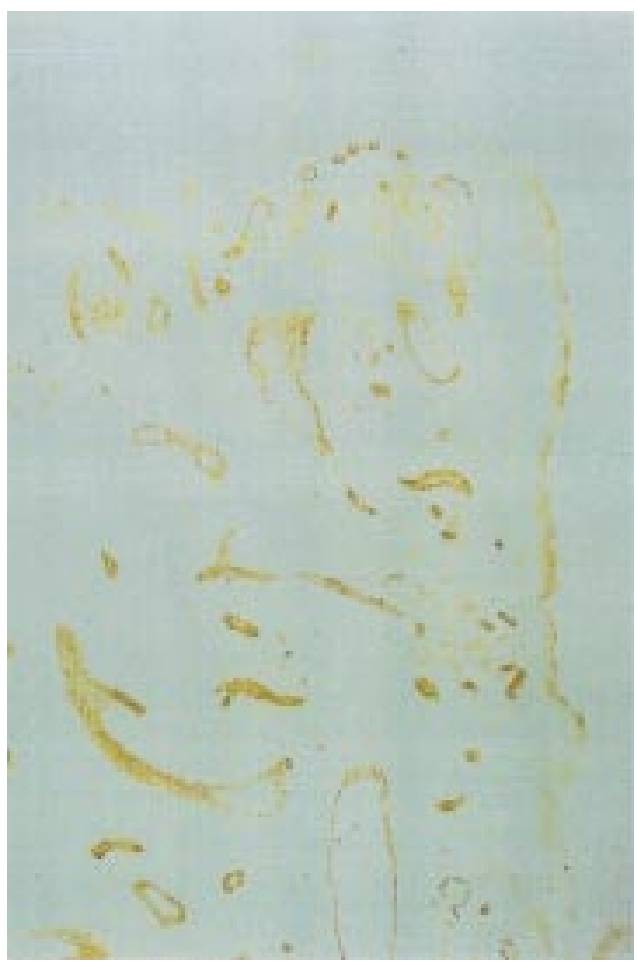

Figure 4 Rheumatoid synovial microvascular endothelium identified immunohistochemically by QBend 30. evidence of bone erosion (hand and feet radiographs). Ten patients were receiving disease modifying anti-rheumatic drugs (three sulphasalazine, three azathioprine, two methotrexate, one gold, one penicillamine).

\section{Synovial biopsy and tissue preparation}

Immediately after MRI examination, patients underwent blind synovial biopsy of the suprapatellar bursa. Subcutaneous tissues were infiltrated with local anaesthetic ( $2 \%$ lignocaine), and multiple biopsy specimens taken using a Parker Pearson synovial biopsy needle (16; Popper and Sons Inc, New York, USA). The needle was positioned to obtain all biopsy specimens from the anterior surface of the suprapatellar bursa and within the range of the needle. Specimens were embedded in optimal temperature cutting compound (OCT; Miles Laboratories, Elkhart, IN), snap frozen using isopentane in liquid nitrogen, and stored at $-70^{\circ} \mathrm{C}$. Cryostat sections were cut at $5 \mu \mathrm{m}-$ $6 \mu \mathrm{m}$.

\section{Immunohistochemistry}

Blood vessels were identified immunohistochemically using the endothelial marker QBend30 (Serotec Ltd, Kidlington, Oxford, UK), by an immunoperoxidase technique. ${ }^{17}$ Endogenous peroxidase activity was blocked by incubating the tissues with $0.3 \% \mathrm{H}_{2} \mathrm{O}_{2}$ in methanol for 30 minutes. The slides were then rinsed in phosphate buffered saline (PBS; two washes of five minutes each). Non-specific binding sites were blocked by incubating the slides in PBS containing $0.05 \%$ bovine serum albumin (BSA) and $0.015 \%$ horse serum for 20 minutes at room temperature. The primary antibody, made up in PBS containing 0.05\% BSA and $0.015 \%$ horse serum, was applied at a dilution of 1:200.

After an incubation period of one hour at room temperature, the sections were rinsed (two washes of five minutes each) in PBS. The binding of the primary monoclonal antibody was detected by the avidin-biotin-peroxidase (ABC) method, ${ }^{18}$ using a Vector Elite biotinylated antimouse ABC kit (Vector Laboratories, Wolfric Square, Peterborough, UK). A standard diaminobenzidine tetrahydrochloride (DAB) enhancement technique was used to increase staining sensitivity. ${ }^{19}$ The slides were then washed in cold running tap water, dehydrated in alcohol, cleared in xylene, and mounted. Tonsil sections served as positive controls, and sections where the primary MAb was omitted as negative controls.

\section{Vascular morphometric assessment}

Only synovium in which the lining was clearly evident was included in the study. Blood vessels greater than $15 \mu \mathrm{m}$ in diameter were quantified throughout the superficial $200 \mu \mathrm{m}$ of synovium in all biopsy specimens using the Symphony image analysis system (SeeScan, Cambridge, UK) and expressed as blood vessel numerical density (number of vessels per square millimetre) and blood vessel fractional area (area enclosed within and including vascular endothelium expressed as a percentage of the 


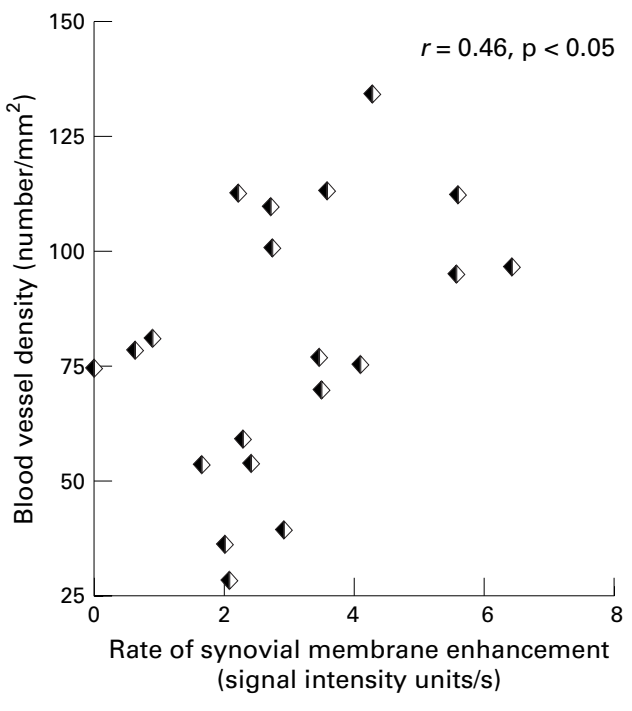

Figure 5 Relation between rate of synovial membrane enhancement and blood vessel numerical density.

total biopsy specimen area) respectively. Vascular morphometric analysis was repeated in one randomly selected biopsy specimen from each patient to assess reproducibility of this technique.

\section{STATISTICAL ANALYSIS}

Data were not normally distributed, therefore, non-parametric statistical methods were applied. All results are reported as medians (interquartile range). Reproducibility measurements were calculated using the interclass correlation " $r$ ". ${ }^{20}$ Other data were compared using Wilcoxon's signed rank test or Spearman's rank correlation coefficient, as appropriate. $p$ Values less than 0.05 were considered significant.

\section{Results}

CONSECUTIVE DAY IMAGING AND REPRODUCIBILITY OF THE MRI QUANTIFICATION TECHNIQUE

Figure 1 is a sagittal section through an RA knee joint before and after intravenous administration of Gd-DTPA. Four of five patients exhibited synovial membrane enhancement on

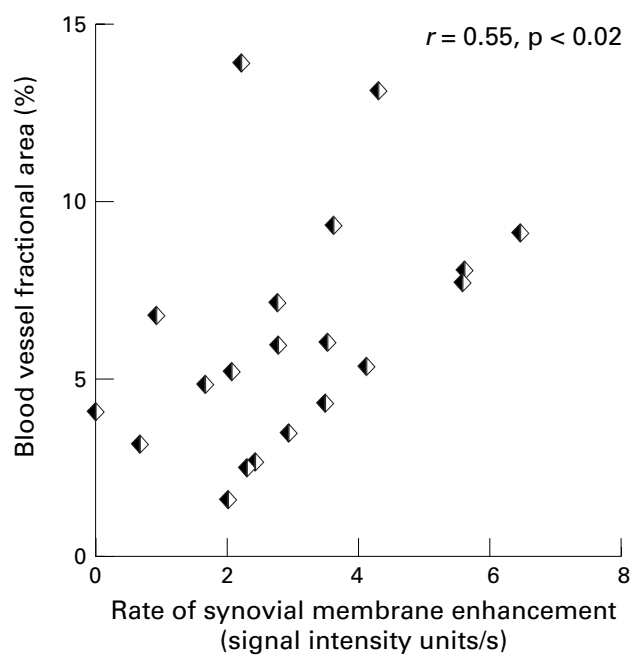

Figure 6 Relation between rate of synovial membrane enhancement and blood vessel fractional area. consecutive days, the fifth patient did not show enhancement on either day. The median change in rate of enhancement was $0(-0.187$ to 0.525 ) signal intensity units/s. The interclass correlation's for consecutive day imaging and the MRI quantification technique were $r_{1}=0.93$ and $r_{1}=0.98$ respectively.

IAP STUDY

The median resting IAP was $16 \mathrm{~mm} \mathrm{Hg}$ (14-20) and median volume of aspirated synovial fluid $14 \mathrm{ml}$ (8-23). Synovial membrane enhancement was observed in nine of 10 patients, median rate 2.93 signal intensity units/s (2.4-3.4). There was no relation between rate of synovial membrane enhancement and IAP (fig 2; $r=-0.091, \mathrm{p}=0.69$ ), however, a significant relation was observed between rate of synovial membrane enhancement and volume of synovial fluid aspirated (fig $3 ; r=0.755, \mathrm{p}<0.05)$.

VASCULAR MORPHOMETRY STUDY

Significant knee movement was detected in one patient who was excluded from the data analysis. Nineteen of the remaining 20 patients exhibited synovial membrane enhancement after administration of Gd-DTPA, median rate 2.7 signal intensity units/s (2.0-3.8). Figure 4 shows the synovial microvascular bed as identified by QBend 30. Ninety eight biopsy specimens were examined; median four specimens per patient (IQR 3-6). The median blood vessel numerical density and fractional area were 77.5 vessels $/ \mathrm{mm}^{2}(56.4-104.9)$ and $5.6 \%(3.8-7.8)$ respectively. An evaluation of the reproducibility of the vascularity quantification system showed that the interclass correlations between blinded duplicate assessments on the same sections $(n=20$, one randomly selected biopsy specimen from each patient) were $r_{1}=0.93$ (numerical density) and $r_{1}=0.95$ (fractional area) respectively. Figures 5 and 6 show the relation between rate of synovial membrane enhancement and blood vessel numerical density $(r=0.46, \mathrm{p}<0.05)$ and blood vessel fractional area $(r=0.55, \mathrm{p}<0.02)$ respectively.

\section{Discussion}

This study describes a reproducible method for quantifying histologically determined synovial vascularity using Gd-DTPA enhanced MRI in rheumatoid patients with knee synovitis. The rate of synovial membrane enhancement correlated with both blood vessel numerical density $(\mathrm{p}<0.05)$ and blood vessel fractional area respectively $(p<0.02)$. IAP did not influence the rate of synovial membrane enhancement.

One of the earliest features of rheumatoid synovitis is the development of a new vascular network, which serves to promote the delivery of cells and nutrients to the invading pannus. ${ }^{21}$ Histological studies in patients with early RA (disease duration less than three years), who had clinical and histological evidence of knee synovitis have shown a significant increase in both vascular proliferation and number of blood vessels per square millimetre as compared with postmortem control samples. ${ }^{22}$ In 
patients with longstanding "burned-out" disease, there is a gradual loss of vascularity resulting in hypervascular pannus being replaced by fibrous tissue. ${ }^{23}{ }^{24}$ Stevens et al examined synovial tissue specimens from rheumatoid patients undergoing knee arthroplasty (mean disease duration 15 years) who by definition had chronic disease. ${ }^{25}$ Synovial capillaries were buried at a modal depth of $75 \mu \mathrm{m}$, approximately twice that found in normal synovium, with a numerical density of $80.2 \mathrm{~mm}^{2}$, approximately one third of normal. In clinically unaffected knee joints, the number of vessels per square millimetre is similar to control samples and vascular proliferation is not seen even though perivascular mononuclear cell proliferation and synovial lining layer thickening may be evident. ${ }^{22}$ These findings suggest that angiogenesis represents a critical stage in the evolution and progression of synovitis.

The role of neovascularisation in the pathogenesis of RA is supported by other findings. Angiogenic cytokines have been demonstrated in rheumatoid synovial biopsy specimens; platelet derived growth factor, tumour necrosis factor $\alpha(\mathrm{TNF} \alpha)$, interleukin 8 (IL8), Gro $\alpha$, and vascular endothelial growth factor $\left(\mathrm{VEGF}^{26}\right)$. VEGF is a hypoxia induced endothelial cell selective mitogen and mediator of changes in synovial permeability, which has been demonstrated in both SF and synovium from active RA patients. ${ }^{27-29}$ It is therefore a potentially key mediator of the microvascular changes seen early in the pathogenesis of RA. ${ }^{30}$ Antibodies to VEGF have been found to partially neutralise the proliferative activity of endothelial cells in RA tissue explant cultures, ${ }^{28}$ and in the rat model of collagen induced arthritis, angiogenesis inhibitors prevent the onset of collagen induced arthritis, suppress established disease, ${ }^{31}{ }^{32}$ and reduce serum concentrations of VEGF. ${ }^{33}$ The effects of certain anti-rheumatic drugs - gold salts, D-penicillamine, methotrexate, anti-TNF $\alpha$ - are known to be partly mediated by changes in vascular endothelium..$^{34-36}$

Although we have shown that the rate of synovial membrane enhancement relates to histologically determined synovial vascularity, rate of enhancement is a complex process, which also reflects changes in synovial perfusion and microvascular permeability. ${ }^{133}$ Xenon clearance and laser Doppler flowmetry studies indicate increased synovial perfusion, ${ }^{1137-39}$ and radionucleotide studies indicate increased synovial permeability ${ }^{40-42}$ in patients with inflammatory arthritis, however, these variables have proved difficult to quantify in a reproducible fashion. It was beyond the scope of our study to calculate the contributions from synovial perfusion and synovial permeability to the "enhancement" equation. This may explain why the correlation demonstrated between rate of synovial membrane enhancement and histologically determined synovial vascularity was not more statistically significant. To explore the precise physiological mechanisms of "enhancement" further, three dimensional MRI studies at high resolution combined with three dimensional volume imaging and principal component analysis would be needed.

Resting IAP is at or below atmospheric pressure in normal joints becoming more subatmospheric during periods of exercise. $.^{92} 43-45$ Low IAP facilitates the flow of fluid into the joint, preserves capillary patency, and ensures that tissue blood supply and nutrition are maintained. In contrast, patients with RA have significantly higher IAP at rest, rising further during exercise. ${ }^{11}{ }^{12} 45$ Artificial volume expansion of both normal and rheumatoid knees (thereby mimicking the effect of an effusion) also increases IAP, the highest pressures being generated in rheumatoid subjects. ${ }^{12} 43446$ In addition, when an external pressure cuff is applied to rheumatoid knee joints with effusions, even modest increasess in IAP $(20 \mathrm{~mm}$ $\mathrm{Hg}$ ) compromise synovial blood flow. ${ }^{47}$ If IAP exceeded capillary perfusion pressure (estimated to be between 30 and $60 \mathrm{~mm} \mathrm{Hg}$ ), synovial uptake of Gd-DTPA could theoretically be compromised, potentially limiting the ability of this technique for assessing synovial vascularity. In our studies, we did not demonstrate a significant relation between IAP and rate of synovial membrane enhancement, however, there was a significant positive correlation between rate of enhancement and volume of synovial fluid aspirated. These data suggest that IAP does not significantly influence rate of Gd-DTPA uptake by synovium in the rheumatoid knee joint, however, because IAP was measured in the joint cavity itself, whereas MRI was undertaken in the SPB, IAP may not have been the same at both sites because of loculation or compartmentalisation of synovial fluid. The positive correlation between IAP and synovial fluid volume may provide indirect evidence for a relation between synovial enhancement and inflammatory activity as synovial fluid volume itself may be an indicator of inflammatory activity within an individual joint. ${ }^{48}$

This work describes for the first time the relation between Gd-DTPA enhanced MRI and a quantitative histological measure of disease state. Our findings support the view that Gd-DTPA enhanced MRI may allow us to distinguish "active" hypervascular pannus from "inactive" fibrous disease, ${ }^{3}$ however further quantitative studies are required to confirm whether this truly represents blood volume or flow or leakage from blood vessels into synovial tissue. Quantifying the rate of synovial membrane enhancement may prove to be a useful technique for evaluating drugs that influence angiogenesis.

We are grateful to the staff of the MRI Department, Royal London Hospital, John Holman, PhD, The Hill Centre, Paul Mapp, $\mathrm{PhD}$, David Walsh, PhD, Bone and Joint Research Unit, St Bartholomew's and The Royal London School of Medicine and Dentistry for technical assistance and advice. This work was supported by a grant from the Arthritis and Rheumatism Council.

1 Gaffney K, Cookson J, Blake DR, Coumbe A, Blades S. Quantification of rheumatoid synovitis by magnetic resonance imaging. Arthritis Rheum 1995;38:1610-17.

2 Tamai K, Yamato M, Yamaguchi T, Ohno W. Dynamic magnetic resonance imaging for the evaluation of synovitis in patients with rheumatoid arthritis. Arthritis Rheum 1994;37:1151-7. 
3 Konig $\mathrm{H}$, Sieper J, Wolf KJ. Rheumatoid arthritis: evaluation of hypervascular and fibrous pannus with dynamic MR imaging enhanced with Gd-DTPA. Radiology 1990;176: 473-7.

4 Bjorkengren AG, Geborek P, Rydholm U, Holtas S, Petterson $\mathrm{H}$. MR imaging of the knee in acute rheumatoid arthritis: Synovial uptake of gadolinium-DOTA. Am J Roentgenol 1990;155:329-32.

5 Ostergaard M, Stoltenberg M, Henriksen O, Lorenzen I. Quantitative assessment of synovial inflammation by dynamic gadolinium-enhanced MRI. A study of the effect of intraarticular methylprednisolone on the rate of early synovial enhancement. Br J Rheumatol 1996;35:50-9.

6 Jevtic V, Rozman B, Watt I, Presetnik M. Use of contrast-enhanced MRI in the assessment of therapeutic response to a disease-modifying antirheumatic drug. Br J Rheumatol 1995;34:956-9.

7 Jevtic V, Watt I, Rozman B, Presetnik M, Logar D, Praprotnik S, et al. Prognostic value of contrast enhanced nik S, et al. Prognostic value of contrast enhanced
Gd-DTPA MRI for development of bone erosive changes in rheumatoid arthritis. Br J Rheumatol 1996;35 (suppl 3): $26-30$

8 Weinmann H-J, Brasch RC, Press W-R, Wesbye GE. Characteristics of gadolinium-DTPA complex: A potential NMR contrast agent. Am J Roentgenol 1984;142:619-24.

9 Levick JR. An investigation into the validity of subatmospheric pressure recordings from synovial fluid and their dependence on joint angle. J Physiol 1979;289:55-67.

10 Levick JR. Synovial fluid and trans-synovial flow in stationary and moving normal joints. In:Helminen HJ, Kiviranta I, Saamanen AM, Tammi M, Paukkonen K, Jurvelin J, eds. foint loading. Bristol: Wright, 1987:149-86.

11 Blake DR, Merry P, Unsworth J, Kidd BL, Outhwaite J, Morris CJ, et al. Hypoxic-reperfusion injury in the inflamed human joint. Lancet 1989;i:289-93

12 Gaffney K, Williams RB, Jolliffe VA, Blake DR. Intraarticular pressure changes in normal and rheumatoid peripheral joints. Ann Rheum Dis 1995;54:670-3.

13 Arnett FC, Edworthy SM, Bloch DA, McShane DJ, Fries JF, Cooper NS, et al. The American Rheumatism Associa$\mathrm{JF}$, Cooper NS, et al. The American Rheumatism Association 1987 revised criteria for the classification of

14 Mallya RK, Mace BEW. The assessment of disease activity in rheumatoid arthritis using a multivariate analysis. Rheumatol Rehabil 1981;20:14-17.

15 Robb RA, Hanson DP. ANALYZE: A software system for biomedical image analysis. In: Proceedings of the First Conference on Visualisation in Medical Computing. Atlanta, GA: IEEE Computer Society, 1990: 507-18.

16 Parker RH, Pearson CM. A simplified synovial biopsy needle. Arthritis Rheum 1963;6:172-5.

17 Fina L, Mogaard NV, Robertson D, Bradley NJ, Monaghan P, Delia D, et al. Expression of CD4 gene in vascular endothelial cells. Blood 1990;75:2417-26.

$18 \mathrm{Hsu}$ SM, Raine L, Fauger H. Use of avidin biotin peroxidase complex (ABC) in immunoperoxidase techniques. J Histo-

19 Hsu SM, Sobane EJ. Color modification of diaminobenzidine (DAB) precipitation by metallic ions and its
application for double immunohistochemistry. J Histoapplication for double immunohisto

20 Armitage P, Berry G. Statistical methods in medical research. 2nd ed. Oxford: Blackwell, 1987: 106-8.

21 Colville-Nash P, Scott DL. Angiogenesis and rheumatoid arthritis: pathogenic and therapeutic implications. Ann Rheum Dis 1992;51:919-25.

22 FitzGerald O, Soden M, Yanni G, Robinson R, Bresnihan B. Morphometric analysis of blood vessels in synovia membranes obtained from clinically affected and unaffected knee joints of patients with rheumatoid arthritis. Ann Rheum Dis 1991;50:792-6.

23 Kelley W. Textbook of rheumatology. Philadelphia: Saunders, 1981.

24 Soden M, Rooney M, Cullen A, Whelan A, Feighery C, Bresnihan B. Immunohistological features in the synovium obtained from clinically uninvolved knee joints of patients with rheumatoid arthritis. Br J Rheumatol 1989;28:28792 .

25 Stevens CR, Blake DR, Merry P, Revell PA, Levick JR. A comparative study by morphometry of the microvasculature in normal and rheumatoid synovium. Arthritis Rheum 1991;50:1508-13.
26 Feldmann M, Brennan FM, Maini RN. Role of cytokines in rheumatoid arthritis. Ann Rev Immunol 1996;14:397-440. 7 Fava RA, Olsen NJ, Spencer-Green G, Yeo KT, Yeo TK, Jackman RW, et al. Vascular permeability factor/endothelial growth factor (VPF/VEGF): accumulation and expression in human synovial fluids and rheumatoid synovial tissue. $\mathrm{J}$ Exp Med 1994;180:341-6.

28 Koch AE, Harlow LA, Haines GK, Amento EP, Unemori EN, Wong WL, et al. Vascular endothelial growth factor. A cytokine modulating endothelial function in rheumatoid arthritis. J Immunol 1994;41:4149-56.

29 Ikeda E, Achen MG, Breier G, Risau W. Hypoxia-induced transcriptional activation and mRNA stability of vascular endothelial growth factor in C6 glioma cells. J Biol Chem 1995;270:19761-6.

30 Paleolog EM. Angiogenesis: A critical process in the pathogenesis of RA - A role for VEGF ? Br J Rheumatol 1996;35:917-20.

31 Peacock DJ, Banquerigo ML, Brahn E. Angiogenesis inhibition suppresses collagen arthritis. J Exp Med 1992;175: $1135-8$

32 Oliver SJ, Banquerigo ML, Brahn E. Suppression of collagen-induced arthritis using an angiogenesis inhibitor, AGM-1470, and a microtubule stabiliser, taxol. Cell Immunol 1994,157:291-9.

33 Oliver SJ, Cheng TP, Banquerigo ML, Brahn E. Suppression of collagen induced arthritis by an angiogenesis nhibitor, AGM-1470, in combination with cyclosporin: reduction in vascular endothelial growth factor (VEGF). Cell Immunol 1995;166:196-206.

34 Matsubara T, Saura R, Hirohata K, Ziff M. Inhibition of human endothelial cell proliferation in vitro and neovascuarisation in vivo by D-penicillamine. J Clin Invest 1989;83:158-67.

35 Hirata S, Matsubara T, Saura R, Tateishi H, Hirohata K. Inhibition of in vitro vascular endothelial cell proliferation and in vitro neovascularisation by low dose methotrexate. Arthritis Rheum 1989;32:1065-73.

36 Elliot MJ, Maini RN, Feldmann M, Long-Fox A, Charles P, Katsikis $\mathrm{P}$, et al. Treatment of rheumatoid arthritis with chimeric monoclonal antibodies to tumor necrosis factor $\alpha$. Arthritis Rheum 1993;36:1681-90.

37 Dick WC, Whaley K, St Onge RA, Downie WW, Boyle JA, Nuki G, et al. Clinical studies on inflammation in human knee joints. Xenon clearances correlated with clinical assessment in various arthritides and studies on the effect of intra-articularly administered hydrocortisone in rheumatoid arthritis. Clin Sci 1970;38:123-33.

38 Dick WC, St Onge RA, Gillespie FC, Downie WW, Nuki G, Gordon I, et al. Derivation of knee joint synovial perfusion using the Xenon $\left({ }^{133} \mathrm{Xe}\right)$ clearance technique. Ann Rheum Dis 1970;29:131-4.

39 Goetzl EJ, Falchuck KH, Zeiger LS. A physiological approach to the assessment of disease activity in rheumatoid arthritis. J Clin Invest 1971;50:1167-80.

40 Harris R, Millard JB, Barerjee SK. Radiosodium clearance from the knee joint in a rheumatoid arthritis. Ann Rheum is $1958 ; 17: 189-95$.

41 Rodnan GP, Maclachlan MJ. The absorption of serum albumin and gamma globulin from the knee joint of man and rabbit. Arthritis Rheum 1960;3:71-7.

42 St Onge RA, Dick WC, Bell G, Boyle JA. Radioactive Xenon $\left({ }^{133} \mathrm{Xe}\right)$ disappearance rates from the synovial cavity of the human knee joint in normal and arthritic subjects. Ann Rheum Dis 1968;27:163-6.

43 Jayson MIV, Dixon A StJ. Intra-articular pressure in heumatoid arthritis of the knee. 1 Pressure changes during passive joint distension. Ann Rheum Dis 1970;29:261-5.

44 Jayson MIV, Dixon A StJ. Intra-articular pressure changes in rheumatoid arthritis of the knee. III Pressure changes during joint use. Ann Rheum Dis 1970;29:401-8.

45 Eyering EJ, Murray W. The effect of joint position on the pressure of intra-articular effusions. J Bone Joint Surg Am 1964;46:1235-41.

46 De Andrade JR, Grant C, Dixon A StJ. Joint distension and reflex muscle inhibition in the knee. J Bone Joint Surg Am 965;47:313-22.

47 Geborek P, Forslind K, Wollheim FA. Direct assessment of synovial blood flow and its relation to induced hydrostatic pressure changes. Ann Rheum Dis 1989;48:281-6.

48 Collins AJ, Cosh JA. Temperature and biochemical studies of joint inflammation. Ann Rheum Dis 1970;29:386-92. 